\title{
Effectiveness of multiple botulinum toxin sessions and the duration of effects in spasticity therapy in children with cerebral palsy
}

\author{
Anna Mirska ${ }^{1} \cdot$ Wojciech Kułak ${ }^{1} \cdot$ Bożena Okurowska-Zawada ${ }^{1} \cdot$ Elżbieta Dmitruk $^{1}$
}

Received: 10 January 2018 / Accepted: 19 July 2018 / Published online: 30 July 2018

(C) The Author(s) 2018

\begin{abstract}
Purpose The aim of this study was to assess the effectiveness of long-term therapy with multiply botulinum neurotoxin (BoNT) injections.

Methods In 2004-2010, 60 children with spastic cerebral palsy aged 2-16 were treated multiple botulinum toxin sessions (injections in gastrocnemius muscle and soleus muscles). In each patient, we rated muscle tone by Modified Ashworth Scale, passive range of motion in ankle joint with extended, and flexed knee joint and gait using the Physician Rating Scale. Assessment was done before and after injection, up to eight BoNT sessions.

Results The generalized additive models showed that a single treatment effect was visible for 3 months. The number of injections did not impact the effectiveness. Improvement in muscle tone was greater in children with hemiplegia than diplegia $(\beta=-0.294$; $p=0.014)$. Improvement in range of motion with extended knee joint was greater in hemiplegic than diplegic types $(\beta=0.414$; $p=0.002$ ), and improvement in range of motion with flexed knee was greater in children with more severe impairment (Gross Motor Function Classification System III vs. I, $\beta=0.0603, p=0.025$; V vs. I, $\beta=0.691, p=0.023$ ). The gait improvement rate decreased with patient age $(p=0.007)$.

Conclusions BoNT therapy is effective regardless of the number of injection sessions and duration of treatment. However, it is affected by the patient's age, type of cerebral palsy, and degree of impairment.
\end{abstract}

Keywords Cerebral palsy $\cdot$ Botulinum toxin $\cdot$ Muscle tone $\cdot$ Range of motion $\cdot$ Gait

\section{Introduction}

Cerebral palsy is a group of permanent disorders in movement and posture development that limits physical activity. It is caused by disruptions in brain development during pregnancy and infancy. Motor disorders are often accompanied by sensory disturbance, cognitive and perception disorders, difficulties in communication, behavior disorders, epilepsy, and secondary issues of the musculoskeletal system. Spasticity is the most common symptom. It initially impairs motor functions and gradually contributes to osteo-articular malformation [1].

Botulinum neurotoxin (BoNT) is a spasticity treatment in children with cerebral palsy [2]. Intramuscular injections inhibit

Anna Mirska

mirska.a@gmail.com

1 Department of Pediatric Rehabilitation and Center of Early Support for Handicapped Children "Give a Chance", Medical University of Bialystok, Waszyngtona 17, 15-274 Białystok, Poland secretion of acetylcholine by neuromuscular synapses. In effect, the muscle is not stimulated, and thus muscle tone decreases [3]. This enables the subject to overcome some spasticity consequences. BoNT treatment is often applied long term. It is recommended to start this in the second year of life and to continue to age $8-10$ years via multiple injections. However, it should not be applied more than once every 3 months because secondary resistance and overlaying dose effects may appear [4].

The efficacy of BoNT therapy is affected by the dose, administration, patient age, and type of parallel rehabilitation [5-7]. Long-term studies comparing the effects of BoNT treatment after each injection are rare [8]. Previous studies have shown that BoNT therapy is effective and therefore is currently a common clinical procedure in cerebral palsy [4-6]. However, there is a need to investigate if multiply injections weaken the therapeutic effects as well as to identify the optimal interval between injections to maintain the best possible improvement. The aim of this study was to assess the effectiveness of long-term therapy with multiply BoNT injections including the time of observed improvement. 


\section{Methods}

\section{Patients}

From 2004 to 2010, 60 patients aged 2 to $16(5.8 \pm 3.4)$ with spastic cerebral palsy were enrolled. Thirty were diagnosed as tetraplegic, 20 diplegic, and 10 hemiplegic. Patients represented different levels of impairment on the Gross Motor Function Classification System (GMFCS) [9]. BoNT (Dysport) was injected into the gastrocnemius and soleus muscles with an average dose of $13.2 \mathrm{j} / \mathrm{kg} / \mathrm{mc}( \pm 3.85)$ as provided for in the national drug program. Over these 6 years, the patients were injected between one and eight times with intervals of 366 months (10 months on average) (Table 1).

\section{Patient's assessment}

The following features were measured in each patient: muscle tone was assessed with the Modified Ashworth Scale (MAS) [10], gait was assessed with the Physician Rating Scale (PRS) [11], and passive range of motion was assessed with the ankle joint with extended (ROM-E) and flexed knee joint (ROM-F). ROM was assessed from 0 to 3 . If flex was not achieved at all,

Table 1 Clinical characteristics of 60 patients with cerebral palsy

\begin{tabular}{|c|c|}
\hline Characteristic & Value \\
\hline \multicolumn{2}{|l|}{ Age } \\
\hline Mean & $5.8 \pm 3.4$ \\
\hline Range & $2-16$ \\
\hline \multicolumn{2}{|l|}{ Sex } \\
\hline Male & 33 \\
\hline Female & 27 \\
\hline \multicolumn{2}{|c|}{ Type of spastic cerebral palsy } \\
\hline Hemiplegia & 10 \\
\hline Diplegia & 20 \\
\hline Tetraplegia & 30 \\
\hline \multicolumn{2}{|l|}{ GMFCS level } \\
\hline I & 3 \\
\hline II & 27 \\
\hline III & 10 \\
\hline IV & 13 \\
\hline $\mathrm{V}$ & 7 \\
\hline \multicolumn{2}{|c|}{ Number of BoNT treatments } \\
\hline 1 & 37 \\
\hline 2 & 19 \\
\hline 3 & 13 \\
\hline 4 & 13 \\
\hline$>5$ & 18 \\
\hline
\end{tabular}

GMFCS Gross Motor Function Classification System, BoNT Botulinum Neurotoxin then the patient was scored with 0 points. If there was a difference between the base and the final position fitted $0^{\circ}-10^{\circ}$ range, then it was scored $1 ; 10^{\circ}-20^{\circ}$ was scored 2 ; and $>20^{\circ}$ was scored 3 . According to the study protocol, patients were rated before and 2 weeks, 6 weeks, and 3 months after injection. In the case of multiple injections, the "before" assessments of the following injections were used to study the duration of therapy improvement (maximally up to 18 months) after previous injection. At that time, all patients were receiving NDT-Bobath rehabilitation, thermotherapy and electrotherapy.

To analyze the effectiveness of the BoNT injections, MAS, PRS, ROM-E, and ROM-F results were measured in the next therapy session, which was 3 to 12 months after the prior injection. In order to check, the effects of multiple injections, data from examination at 2 weeks after each treatment, were only included in this investigation (because the previous study indicated that the improvement was most pronounced during this period) [12]. A similar approach was used to test the relationship between therapy effect and patient age.

\section{Statistical analysis}

The generalized additive model (GAM) was used to test if/ how improvement changed as a function of multiple injections of BoNT. The variables included time elapsed from injection, patient's age, and the number of injections. Link functions and distribution type of the models was decided via the Akaike information criterion (AIC). Models were built with a Gaussian distribution and "identity" link function. These iterations were conducted by adding other variables (type of cerebral palsy and GMFCS level) to assess their influence on improvement gained. Analyses used R software including version 3.3.2 with the "mgcv" package.

\section{Results}

The time elapsed since BoNT injection significantly influenced the change in all features. The change in MAS increased with time while change in ROM-E and ROM-F decreased (Fig. 1). The GAM models showed that the parameters improved up to 3 months after injection, and there was a decline after this point. Stabilization was achieved 10 months from injection.

The number of injections did not affect the outcome parameters (Table 2). Only the change in PRS was significantly affected by patient age. The observed changes were positively affected by age up to 7 years. Beyond this, age was negatively correlated to therapy improvement (Fig. 2).

The type of cerebral palsy as well as impairment level (in GMFCS) influenced the assessments (Table 3). The change in MAS values were lower and higher in ROM-E in hemiplegic vs. diplegic type of cerebral palsy. Scores for hemiplegic patients were improved by 0.294 in MAS and 0.414 in ROM-E 
a)

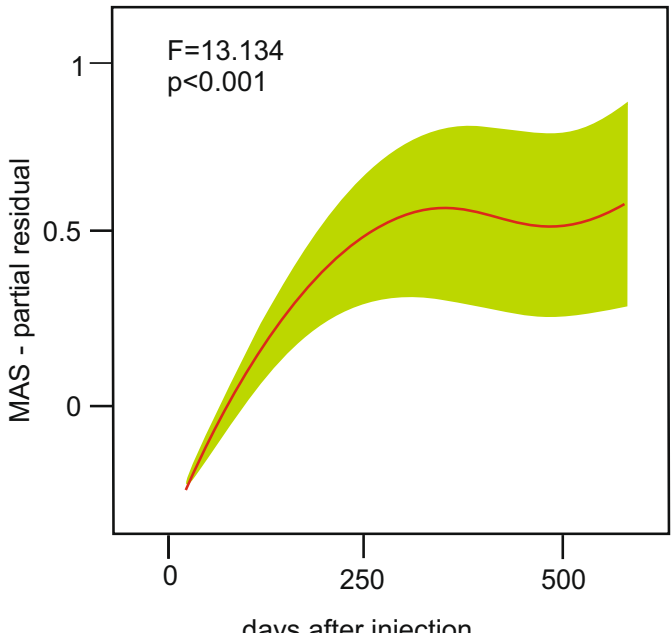

days after injection

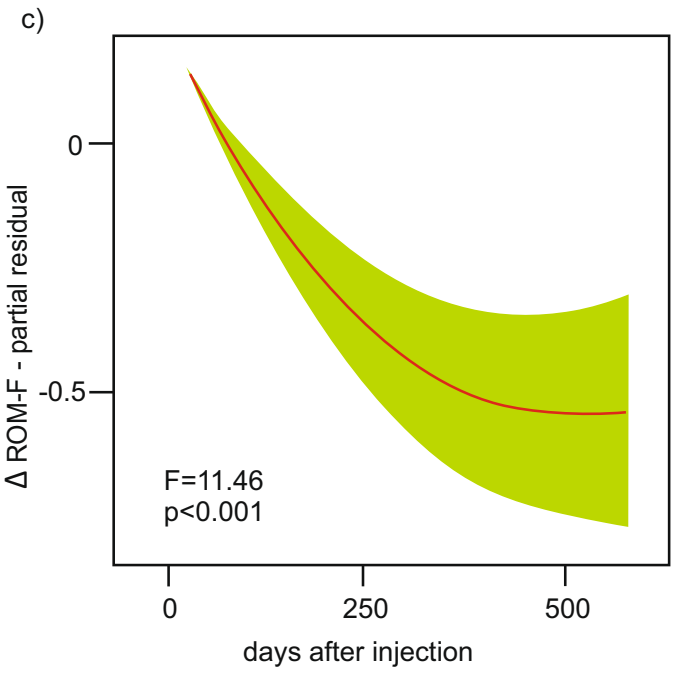

Fig. 1 Generalized additive model models of temporal dynamics of MAS (Modified Ashworth Scale) (a), ROM-E (range of motion in ankle joint with extended knee joint) (b), ROM-F (range of motion in ankle joint
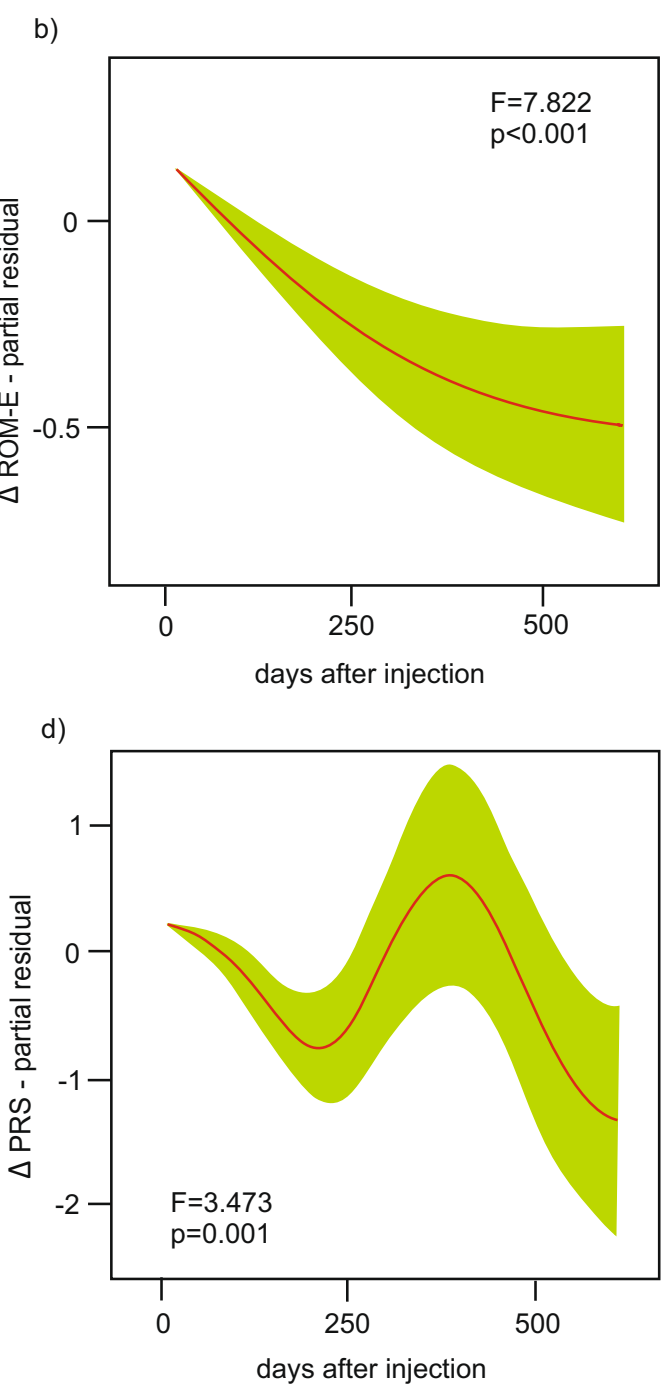

with flexed knee joint) (c), and PRS (Physician Rating Scale) (d); $\Delta$ is the difference between post-injection and pre-injection scores

Table 2 General additive model results for clinical assessments used to study the effectiveness of botulinum neurotoxin (BoNT) treatment after 2 weeks at the injection

\begin{tabular}{|c|c|c|c|c|c|c|c|c|c|}
\hline \multirow[t]{3}{*}{ Parameter } & \multirow[t]{3}{*}{$\begin{array}{l}\text { Observed } \\
\text { change (mean; } \pm \text { ) }\end{array}$} & \multicolumn{4}{|c|}{ Two-factor models } & \multicolumn{4}{|c|}{$\begin{array}{l}\text { Four-factor models, including effects of type of cerebral } \\
\text { palsy and GMFCS level }\end{array}$} \\
\hline & & \multicolumn{2}{|c|}{ Number of BoNT treatments } & \multicolumn{2}{|c|}{ Patient's age } & \multicolumn{2}{|c|}{ Number of BoNT treatments } & \multicolumn{2}{|c|}{ Patient's age } \\
\hline & & $\mathrm{F}$ & $p$ & $\mathrm{~F}$ & $p$ & $\mathrm{~F}$ & $p$ & $\mathrm{~F}$ & $p$ \\
\hline$\triangle$ MAS & $-0.49 \pm 0.44$ & 0.127 & 0.722 & 0.467 & 0.6 & 0.169 & 0.682 & 0.101 & 0.744 \\
\hline$\Delta$ ROM-E & $0.36 \pm 0.48$ & 1.02 & 0.385 & 1.139 & 0.288 & 2.244 & 0.156 & 0.234 & 0.63 \\
\hline$\Delta \mathrm{ROM}-\mathrm{F}$ & $0.37 \pm 0.44$ & 0.79 & 0.38 & 1.425 & 0.206 & 1.067 & 0.275 & 1.2387 & 0.278 \\
\hline$\Delta$ PRS & $0.90 \pm 1.15$ & 0.022 & 0.884 & 7.491 & 0.007 & 0.043 & 0.836 & 6.083 & 0.016 \\
\hline
\end{tabular}

MAS Modified Ashworth Scale, ROM-E passive range of motion in ankle joint with extended knee joint, $R O M-F$ passive range of motion in ankle joint with flexed knee joint, $P R S$ Physician Rating Scale; $\Delta$ is the difference between post-injection and pre-injection scores 


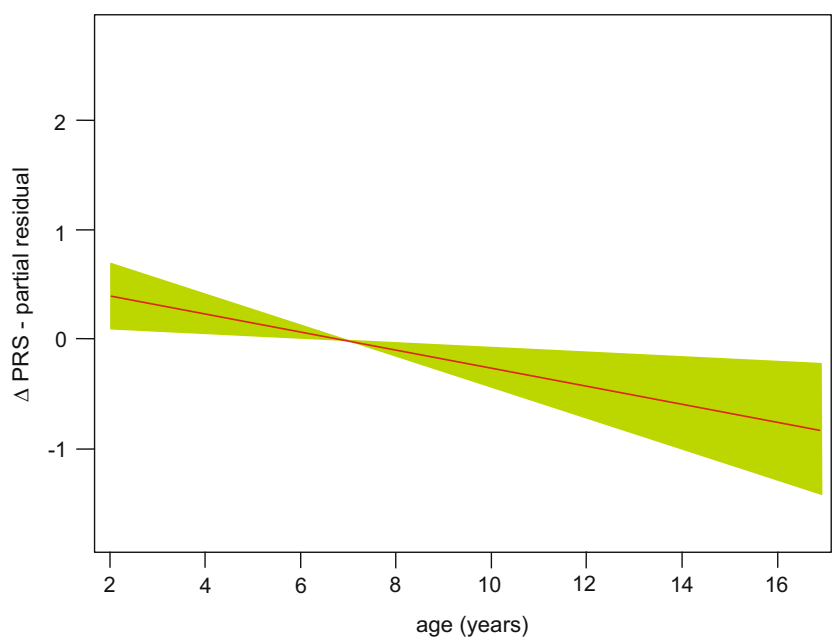

Fig. 2 Generalized additive model of change in Physician Rating Scale (PRS) with patient's age. $\Delta$ is the difference between post-injection and pre-injection scores

compared to diplegic ones. The changes in ROM-F were positively affected by higher than I GMFCS levels: patients scored on levels III and V of GMFCS obtained better results by 0.603 and 0.691 , respectively. Change in PRS values were not affected by the variables tested.

\section{Discussion}

Of the numerous papers focusing on BoNT efficacy, only a few dealt with multiple injections over long-term therapy. In fact, most clinical therapies for spasticity in children with cerebral palsy are conducted in this way. Therefore, the questions raised at the beginning of this paper are relevant to clinical practice.

We have shown that the time elapsed from BoNT injection significantly affected its efficacy. The GAM model showed a gain in tested features by 3 months similar to the results obtained by other authors. The decrease in muscle tone after therapy is known to last for 12 weeks [5, 13], 16 weeks [14, 15], or even up to 6 months [16-18]. However, not all studies have confirmed this last finding $[15,19]$. The improvement in the range of motion $[13,15,16,20]$ as well as in motor functions $[15,17,19,20]$ is a secondary effect of BoNT treatment; this lasts for about 6 months. The models built on clinical data indicate that after improvement in these traits, there is eventual worsening and finally stabilization. After improvement, muscle tone gradually increased up to 10-12 months from injection, while the range of motion in ankle joint began to decrease up to around 16 months.

The primary effects of BoNT therapy are associated with a decrease in muscle tone that is shorter than the secondary effects. Therefore, there are improved motor functions including gait that may last longer [20-22]. In our study, improvement in PRS lasted for 3 months; however, there is still early oscillation (Fig. 1) for reasons that are unclear. PRS assessment involves setting foot in the stance phase of gait cycle and is an accurate tool along with the other parameters used here. Moreover, PRS components like speed of gait, knees position during gait, and degree of crouch, we did not register changes. This would significantly influence the final PRS assessment and also the improvement rate curve. The accuracy of the assessment might be influenced by the fact that it was assessed in real time. The best assessment is supposed to be conducted through split-screen video in a slow-motion facility together with the use of a modified PRS version [3].

The literature shows that each BoNT injection causes desirable pharmacological effect, which decreases muscle tension [23-25]. Tedroff et al. found that BoNT may be effective for long-term spasticity reduction, but not in the prevention of contracture development. They also showed that the best gain in ROM was achieved after the first injection. After subsequent injections, the effect of the increasing range of motion was lower and insignificant [23]. Better improvement after the first injection was also observed by Linder et al. [24] and FattalValevski et al. [25]; however, assessments of motor functions with the GMFM test showed identical improvements.
Table 3 Generalized additive model significance test results for changes in values of clinical assessments after BoNT treatments ( 2 weeks after the injection) were tested as a function of cerebral palsy type and impairment level

\begin{tabular}{lcccc}
\hline Variables & Regression parameter & SE & $t$ & $p$ \\
\hline$\Delta$ MAS & & & & \\
Intercept & -0.776 & 0.23 & -3.38 & 0.001 \\
Hemiplegic vs. diplegic & -0.294 & 0.118 & -2.499 & 0.014 \\
$\Delta$ ROM-E & & & & \\
Intercept & -0.077 & 0.25 & -0.307 & 0.76 \\
Hemiplegic vs. diplegic & 0.414 & 0.13 & 3.172 & 0.002 \\
$\Delta$ ROM-F & & & & \\
Intercept & 0.005 & 0.237 & 0.022 & 0.983 \\
GMFCS level III vs. GMFCS level I & 0.603 & 0.264 & 2.286 & 0.025 \\
GMFCS level V vs. GMFCS level I & 0.691 & 0.298 & 2.321 & 0.023 \\
\hline
\end{tabular}

MAS Modified Ashworth Scale, $R O M-E$ passive range of motion in ankle joint with extended knee joint, $R O M-F$ passive range of motion in ankle joint with flexed knee joint, GMFCS Gross Motor Function Classification System; $\Delta$ is the difference between post-injection and pre-injection scores 
Higher and statistically significant gain was noted after the first injection in studies by Papavisilou et al. [26] and FattalValevski et al. [25]. Also, in study by Read et al., a statistically significant gait improvement was especially marked after the first treatment and the effect was maintained also after two following treatments [27]. In addition, Hong et al. found that gait improved more in children with two or fewer injections than in patients with more than two injections [28]. A metaanalysis conducted by Kahraman et al. using studies from 1990 to 2015 showed that the first two injections let to functional improvement in children with spasticity. Unfortunately, they could not compare the effectiveness of more than one therapy repetition due to methodological incompatibilities of the studies included [8]. Our study showed that the number of injections did not affect improvement rate of the tested parameters. Although the sample size differed in groups with different numbers of injections as well as those that differed in the interval between injections.

Only gait had a significant improvement with patient's age. The increase in gait declined with age up to 7 years, worsened further after that (Fig. 2). This is because motor function development in children with cerebral palsy lasts through age 7 [29]; nearly $90 \%$ of motor skills are already achieved by age 5 [30]. Therefore, children between the 1st and 5th year are expected to best respond to BoNT therapy [3], and early age injections help to develop less-pathological gait patterns that control groups [31, 32]. Wissel et al. obtained similar results. Here, the best gain was achieved in children below 7 years old both in gait and muscle tone [33].

The other parameters assessed were not affected by patient's age, but some studies found a relation with passive dorsiflexion in ankle joint $[34,35]$. This might be because younger children have more spastic muscles than those with a fixed contracture [36]. Eames et al. suggested that BoNT treatment efficacy is no longer by patient age once a fixed contracture appeared in the muscle [37]. The most effective approach would therefore be to start BoNT therapy while the muscle is still in a dynamic contracture phase. The same authors have suggested that the frequency of structural modifications increase with patient's age; this decreases therapy efficacy in older children [37]. However, this does not mean that BoNT therapy is useless in improving the range of motion in older children $[38,39]$.

We found other factors that influence the effectiveness of therapy including type of cerebral palsy and motor impairment level. Children with hemiplegia had better improvement in muscle tone as well as in range of motion than children with diplegia. Moreover, children with higher than type I GMFCS level showed a greater gain in their range of motion. Other studies on BoNT treatment in cerebral palsy did not confirm the impact of cerebral palsy type nor impairment level in gross motor functions for muscle tone or range of motion [40, 41]. However, Fazzi et al. did show that these factors affected gait quality (PRS) and selective motor control [41]. Both outcomes were better in children with hemiplegia and milder motor impairment.

\section{Conclusion}

Our study showed BoNT therapy is effective in children with cerebral palsy regardless of the number of sessions. Best results were achieved in children under age 7 with hemiplegia and greater impairment than level I on the GMFCS scale. The treatment gain was highest up to 3 months after injection. Therefore, BoNT therapy can be safely and effectively repeated every 3-6 months.

Acknowledgements The authors wish to thank Katarzyna Cybula for carrying out patient's assessment.

\section{Compliance with ethical standards}

The study was approved by the Ethics Committee of the Medical University of Bialystok, Poland. Informed consent was obtained from the parents.

Conflict of interest On behalf of all authors, the corresponding author states that there is no conflict of interest.

Open Access This article is distributed under the terms of the Creative Commons Attribution 4.0 International License (http:// creativecommons.org/licenses/by/4.0/), which permits unrestricted use, distribution, and reproduction in any medium, provided you give appropriate credit to the original author(s) and the source, provide a link to the Creative Commons license, and indicate if changes were made.

\section{References}

1. Morris C (2007) Definition and classification of cerebral palsy: a historical perspective. Dev Med Child Neurol 49:3-7. https://doi. org/10.1111/j.1469-8749.2007.tb12609.x

2. Koman LA, Smith BP, Balkrishnan R (2003) Spasticity associated with cerebral palsy in children. Pediatr Drugs 5:11-23. https://doi. org/10.2165/00128072-200305010-00002

3. Graham HK, Aoki KR, Autti-Rämö IG, Boyd RN, Delgado MR, Gaebler-Spira DJ, Gormley ME Jr, Guyer BM, Heinen F, Holton AF, Matthews D, Molenaers G, Motta F, García Ruiz PJ, Wissel J (2000) Recommendations for the use of botulinum toxin type A in the management of cerebral palsy. Gait Posture 11:67-79. https:// doi.org/10.1016/S0966-6362(99)00054-5

4. Heinen F, Desloovere K, Schoroeder AS et al (2010) The update European consensus 2009 on the use of botulinum toxin for children with cerebral palsy. Eur J Paediatr Neurol 14:45-66. https:// doi.org/10.1016/j.ejpn.2009.09.005

5. Scholtes VA, Dallmeijer AJ, Knol DL, Speth LA, Maathuis CG, Jongerius PH, Becher JG (2007) Effect of multilevel botulinum toxin a and comprehensive rehabilitation on gait in cerebral palsy. Pediatr Neurol 36:30-39. https://doi.org/10.1016/j.pediatrneurol. 2006.09.010 
6. Heinen F, Molenaers G, Fairhurst C, Carr LJ, Desloovere K, Chaleat Valayer E, Morel E, Papavassiliou AS, Tedroff K, Ignacio Pascual-Pascual S, Bernert G, Berweck S, di Rosa G, Kolanowski E, Krägeloh-Mann I (2006) European consensus table 2006 on botulinum toxin for children with cerebral palsy. Eur J Paediatr Neurol 10:215-225. https://doi.org/10.1016/j.ejpn.2006. 08.006

7. Wang Y, Gao B (2008) A dose-response relationship research on botulinum toxin type a local intramuscular injections of lower extremity spasticity in children with cerebral palsy. Child Nerv Syst 24:545-547. https://doi.org/10.1007/s00381-007-0571-7

8. Kahraman A, Seyhan K, Değer Ü, Kutlutürk S, Mutlu A (2016) Should botulinum toxin a injections be repeated in children with cerebral palsy? A systematic review. Dev Med Child Neurol 58: 910-917. https://doi.org/10.1111/dmcn.13135

9. Rosenbaum PL, Palisano RJ, Bartlett DJ, Galuppi BE, Russell DJ (2008) Development of the Gross Motor Function Classification System for cerebral palsy. Dev Med Child Neurol 50:249-253. https://doi.org/10.1111/j.1469-8749.2008.02045.x

10. Bohannon RW, Smith M (1987) Interrater reliability of a modified Ashworth scale of muscle spasticity. Phys Ther 67:206-207. https:// doi.org/10.1093/ptj/67.2.206

11. Koman LA, Brashear A, Rosenfeld S, Chambers H, Russman B, Rang M, Root L, Ferrari E, Garcia de Yebenes Prous J, Smith BP, Turkel C, Walcott JM, Molloy PT (2001) Botulinum toxin type a neuromuscular blockade in the treatment of equinus foot deformity in cerebral palsy: a multicenter, open-label clinical trial. Pediatrics 108:1062-1071. https://doi.org/10.1542/peds.108.5.1062

12. Mirska A, Cybula K, Okurowska-Zawada B, Kułak W, Dmitruk E, Okulczyk K, Kalinowska AK (2014) Use of botulinum toxin in the treatment of ankle plantar flexor spasticity in children with cerebral palsy. J Pediatr Orthop B 23:517-522. https://doi.org/10.1097/ BPB.0000000000000098

13. Lee JH, Sung IY, Yoo JY, Park EH, Park SR (2009) Effects of different dilutions of botulinum toxin type A treatment for children with cerebral palsy with spastic ankle plantarflexor: a randomized controlled trial. J Rehabil Med 41:740-745. https://doi.org/10. 2340/16501977-0418

14. Sarioglu B, Serdaroglu G, Tutuncuoglu S, Ozer EA (2003) The use of botulinum toxin type a treatment in children with spasticity. Pediatr Neurol 29:299-301. https://doi.org/10.1016/S08878994(03)00269-8

15. Colovic H, Dimitrijevic L, Stankovic I, Nikolic D, RadovicJanosevic D, Zivanovic D (2014) The effects of botulinum toxin type a on improvement and dynamic spastic equinus correction in children with cerebral palsy - preliminary. Arch Med Sci 10:979984. https://doi.org/10.5114/aoms.2014.46217

16. Scholtes VA, Dallmeijer AJ, Knol DL, Speth LA, Maathuis CG, Jongerius PH, Becher JG (2006) The combined effect of lower-limb multilevel botulinum toxin type a and comprehensive rehabilitation on mobility in children with cerebral palsy: a randomized clinical trial. Arch Phys Med Rehabil 87:1551-1558. https://doi.org/10. 1016/j.apmr.2006.08.342

17. Flett PJ, Stern LM, Waddy H, Connell TM, Seeger JD, Gibson SK (1999) Botulinum toxin A versus fixed cast stretching for dynamic calf tightness in cerebral palsy. J Paediatr Child Health 35:71-77. https://doi.org/10.1046/j.1440-1754.1999.00330.x

18. Camargo CH, Teive HA, Zonta M et al (2009) Botulinum toxin type A in the treatment of lower-limb spasticity in children with cerebral palsy. Arq Neuropsiquiatr 67:62-68. https://doi.org/10. 1590/S0004-282X2009000100016

19. Unlu E, Cevikol A, Bel B, Gonen E, Celik O, Kose G (2010) Multilevel botulinum toxin type A as a treatment for spasticity in children with cerebral palsy: a retrospective study. Clinics 65(6): 613-619. https://doi.org/10.1590/S1807-59322010000600009
20. Love SC, Valentine JP, Blair EM, Price CJ, Cole JH, Chauvel PJ (2001) The effect of botulinum toxin type A on the functional ability of the child with spastic hemiplegia a randomized controlled trial. Eur J Neurol 8(Suppl 5):50-58

21. Sławek J, Klimont L (2003) Functional improvement in cerebral palsy patients treated with botulinum toxin A injections - preliminary results. Eur J Neurol 10(3):313-317. https://doi.org/10.1046/j. 1468-1331.2003.00582.x

22. Bottos M, Benedetti MG, Salucci P, Gasparroni V, Giannini S (2003) Botulinum toxin with and without casting in ambulant children with spastic diplegia: a clinical and functional assessment. Dev Med Child Neurol 45:758-762. https://doi.org/10.1111/j.14698749.2003.tb00885.x

23. Tedroff K, Granath F, Forssberg H, Haglund-Akerlind Y (2009) Long-term effects of botulinum toxin A in children with cerebral palsy. Dev Med Child Neurol 51:120-127. https://doi.org/10.1111/ j.1469-8749.2008.03189.x

24. Linder M, Schindler G, Michaelis U, Stein S, Kirschner J, Mall V, Berweck S, Korinthenberg R, Heinen F (2001) Medium-term functional benefits in children with cerebral palsy treated with botulinum toxin type A: 1-year follow-up using gross motor function measure. Eur J Neurol 8(Suppl 5):120-126

25. Fattal-Valevski A, Domenievitz D, Giladi N, Wientroub S, Hayek S (2008) Long-term effect of repeated injections of botulinum toxin in children with cerebral palsy: a prospective study. J Child Orthop 2: 29-35. https://doi.org/10.1007/s11832-007-0075-8

26. Papavasiliou A, Rapidi CA, Filiopoulos C, Rizou C, Skouteli HN (2006) Evaluation of multimodal management of prematurityrelated spasticity. Pediatr Neurol 35:400-407. https://doi.org/10. 1016/j.pediatrneurol.2006.08.003

27. Read FA, Boyd RN, Baber LA (2017) Longitudinal assessment of gait quality in children with bilateral cerebral palsy following repeated lower limb intramuscular botulinum toxin-A injections. Res Dev Disabil 68:35-41. https://doi.org/10.1016/j.ridd.2017.07.002

28. Hong BY, Chang HJ, Lee SJ, Lee S, Park JH, Kwon JY (2017) Efficacy of repeated botulinum toxin type a injections for spastic equinus in children with cerebral palsy - a secondary analysis of the randomized clinical trial. Toxins 9:253. https://doi.org/10.3390/ toxins 9080253

29. Harries N, Kassirer M, Amichai T, Lahat E (2004) Changes over years in gross motor function of 3-8 year children with cerebral palsy: using the gross motor function measure (GMFM-88). Isr Med Assoc J 6:408-411

30. Rosenbaum PL, Walter SD, Hanna SE, Palisano RJ, Russell DJ, Raina P, Wood E, Bartlett DJ, Galuppi BE (2002) Prognosis for gross motor function in cerebral palsy: creation of motor development curves. JAMA 288:1357-1363. https://doi.org/10.1001/jama. 288.11.1357

31. Desloovere K, Molenaers G, De Cat J et al (2007) Motor function following multilevel botulinum toxin type A treatment in children with cerebral palsy. Dev Med Child Neurol 49:56-61. https://doi. org/10.1111/j.1469-8749.2007.014xa.x

32. Zonta MB, Bruck I, Puppi M, Muzzolon S, Neto AC, Santos LHC (2013) Effects early spasticity treatment on children with hemiplegic cerebral palsy: a preliminary study. Arq Neuropsiquiatr 71:453461. https://doi.org/10.1590/0004-282X20130061

33. Wissel J, Heinen F, Schenkel A, Doll B, Ebersbach G, Müller J, Poewe W (1999) Botulinum toxin A in the management of spastic gait disorders in children and young adults with cerebral palsy: a randomized, double-blind study of "high-dose" versus "low-dose" treatment. Neuropediatrics 30:120-124. https://doi.org/10.1055/s2007-973475

34. Cosgrove AP, Corry IS, Graham HK (1994) Botulinum toxin in the management of the lower limb. Dev Med Child Neurol 30:386396. https://doi.org/10.1111/j.1469-8749.1994.tb11864.x 
35. Chutorian AM, Root L (1994) Management of spasticity in children with botulinum toxin A. Intl Paediatric 9(Suppl):35-43

36. de Paiva A, Muenier FA, Molgo J, Aoki KR, Dolly JO (1999) Functional repair of motor endplates after botulinum neurotoxin type A poisoning: biphasic switch of synaptic activity between nerve sprouts and their parent terminals. Proc Natl Acad Sci U S A 96:3220-3225. https://doi.org/10.1073/pnas.96.6.3200

37. Eames NW, Baker R, Hill N, Graham K, Taylor T, Cosgrove A (1999) The effect of botulinum toxin A on gastrocnemius length and duration of response. Dev Med Child Neurol 41:226-232. https://doi.org/10.1111/j.1469-8749.1999.tb00589.x

38. Wissel J, Müller J, Baldauf A, Ung SC, Ndayisaba JP, Stöckl B, Frischhut B, Haberfellner H, Poewe W (1999) Gait analysis to assess the effects of botulinum toxin type A treatment in cerebral palsy: an open-label study in ten children with equinus gait pattern.
Eur J Neurol 6(Suppl 4):23-35. https://doi.org/10.1111/j.14681331.1999.tb00037.x

39. Autti-Rämö I, Larsen A, Peltonen J, Heinen F (1997) The use of botulinum toxin treatment in children with movement disorders. Eur J Neurol 4(Suppl 2):23-26

40. Fattal-Valevski A, Giladi N, Domanievitz D, Zuk L, Masterman R, Harel S, Wientroub S, Hayek S (2002) Parameters for predicting favorable responses to botulinum toxin in children with cerebral palsy. J Child Neurol 17(4):272-276. https://doi.org/10.1177/ 088307380201700407

41. Fazzi E, Maraucci I, Torrieli S, Motta F, Lanzi G (2005) Factors predicting the efficacy of botulinum toxin-A treatment of the lower limb in children with cerebral palsy. J Child Neurol 20:661-666. https://doi.org/10.1177/08830738050200080501 